\title{
THE LEADING EDGE FIRE FIGHTING ROBOT - A STUDY
}

\author{
Vishal Singh, Sudhanshu Srivastava, Naman Shukla, Tejal Singh \\ Department of EC \\ IMS Engineering College \\ Ghaziabad, Uttar Pradesh, India
}

\begin{abstract}
In today's world nothing is exactly predictable about any accidents or mishapenings and for that we are just supposed to be highly active and stand strong for any such situations in our daily life. We as an engineer's join hands for making a smart and a better world. Security is all that our life demands and for securing our lives we must need to secure the buildings where we live, the offices, the factories where we work, the laboratories, and what not. So what's going to happen if a building catches fire? Obviously we are going to call the fire extinguishers and they are going to risk their lives for us or sometimes even for small fires user may take a long time in finding water source to extinguish fire. But what if we can control the fire by not getting much close to it and in much lesser time as compared to the manual extinguishing, isn't it interesting? So here we have a leading edge firefighting robot which not only extinguishes fire but also notifies you about the emergency via sms.
\end{abstract}

\section{INTRODUCTION}

Mobile technology has developed every year, from first generation analogues system, new 2G [1] digital system came into account and now they have moved on to 5G [2]. GSM stands for Global System for Mobile Communication, a digital technology that transmits data services and mobile voice. The concept of GSM came from a cell-based mobile radio system at Bell Laboratories in the early 1970s and now it is implemented globally. GSM is a circuit-switched system [3] that divides each 200 $\mathrm{kHz}$ channel into eight $25 \mathrm{kHz}$ time-slots. It operates on the mobile communication bands $900 \mathrm{MHz}$ and $1800 \mathrm{MHz}$ in most parts of the world. GSM uses narrowband Time Division Multiple Access (TDMA) technique [4] for transmission and has 64 kbps to 120 Mbps of data rates. Currently GSM supports more than one billion mobile subscribers in more than 210 countries throughout the world. Other than data and voice services GSM also provides roaming service by which you can use your GSM phone number in another GSM network.

\section{GSM SPECIFICATIONS}

The modulation technique used for the GSM is Gaussian Minimum Shift Key (GMSK) [5] and the access technique used is Time Division Multiple Access (TDMA) over Frequency Division Duplex (FDD) [6]. In the beginning it was designed to operate at frequency of $900 \mathrm{MHz}$ (uplink: $890-915$ Mhz, downlink: 935-960Mhz) later it was subjected to frequency of $1800 \mathrm{MHz}$. Nowadays GSM works at a frequency of 800 and $1900 \mathrm{Mhz}$. The duplexing technique used in GSM is FDD (Frequency division duplexing) with a frame duration of $4.615 \mathrm{~ms}$. Due to much slow data rate and bitter browsing experience the new advancements were made and they are as

\section{HIGH SPEED CIRCUIT SWITCHED DATA (HSCSD) [7]}

Group of two or more channels were used to increase the data rate but due to involvement of multiple channels for the service the rate was high so it was not used much and hence is less popular. GPRS was introduced to overcome the cons of the GSM.

\section{GENERAL PACKET RADIO SERVICE (GPRS) [8]}

It upgraded the GSM system from circuit switched to packet switched method. It has faster data rate than normal GSM. It uses multiple time slot for single bearer providing better quality and higher data rate. The mobile terminals were classified based on whether it supports GSM, GPRS or both. The rate was further improved with the introduction of EDGE technology.

\section{ENHANCED DATA RATE FOR GLOBAL EVOLUTION (EDGE) [9]}

The improved data rate was achieved by adopting other modulation technique with new coding technique. Nine coding technique is used in EDGE instead of four used in GPRS. The packet window is also increased from 64 to 1024. EDGE is the bridge between $2 \mathrm{G}$ and $3 \mathrm{G}$ system.

\section{GSM SECURITY [10]}

GSM is the most secured cellular telecommunications system available today. GSM maintains end-to-end security. 


\section{AUTHENTICATION}

Authentication in the GSM system is achieved by the base station sending out a challenge to MS [11]. MS uses a SIM to send back the response that is then verified andauthenticates the MS. There is a unique authentication key for every SIM card. When a call starts, a 128 bit random number is generated by the $\mathrm{AuC}$ and transmitted to the SIM card. An A3 algorithm generates a 32 bit output called the SRES. The same process is done on the $\mathrm{AuC}$ side in which the SIM card transmits this SRES number to the $\mathrm{AuC}$ and then AuC compares the received SRES with the SRES that's generated on the network side. The SIM is authenticated if and only if the two SRES are same.

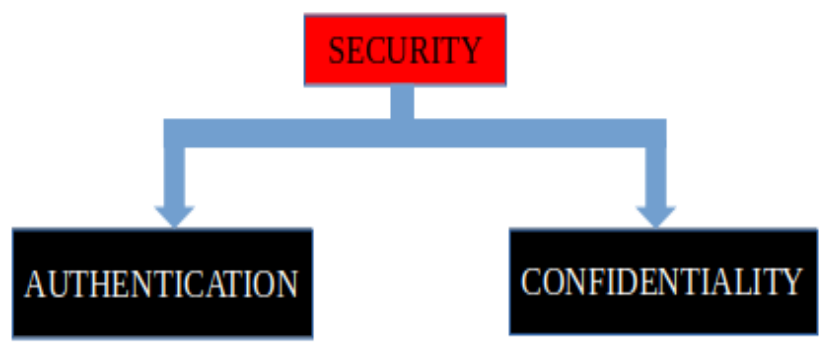

Fig. 1: GSM Security

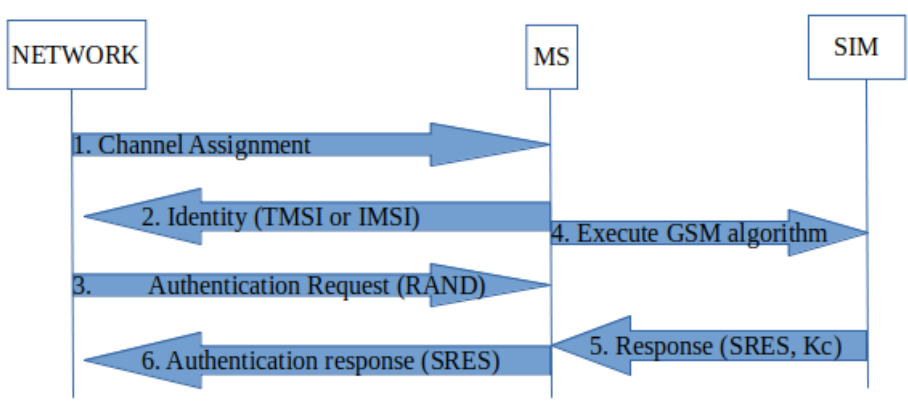

Fig. 2: GSM Authentication

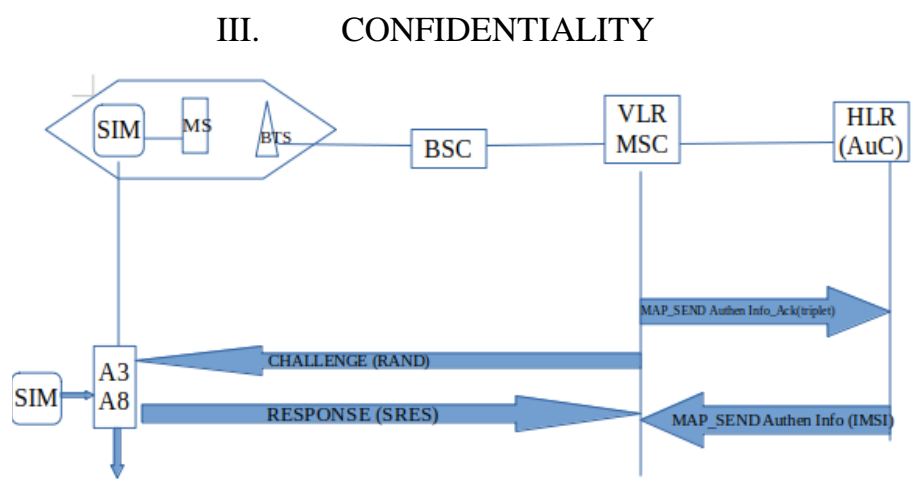

Fig. 3: Confidentiality in GSM

Encryption and decryption of voice and data between MS and the network is accomplished by the use of A3 algorithm [12]. A GSM conversation uses two frames, one from BSS to MS and back from MS to BSS, each frames containing 114 bits of information of the user. These total 228 bits require the encryption to protect from being attacked. The SIM provides the Kc A8 algorithm and generates a key stream of 228 bits through A3 algorithm. These 228 bits are transferred on air interface for increased confidentiality.

\section{WORKING}

The firefighting robot is basically based on the GSM technology. The whole system is mainly controlled by arduino uno [13] which gets active when the three fire sensors used in the robot senses fire. Once the fire is sensed the by fire sensors the arduino gives command to pump which is driven by a relay, arduino also gives command to motor drivers, servo motor, and motor. All these components are given a supply source through a battery. The fire sensors are set by a threshold values and if the value increases than the threshold value then the buzzer starts beeping and GSM module is activated through arduino which then sends sms to the registered mobile notifying

bout the emergency and need for more robots. If the value is below threshold the system handles the situation on its own. This system is very useful to handle such situations easily and saving lives. 


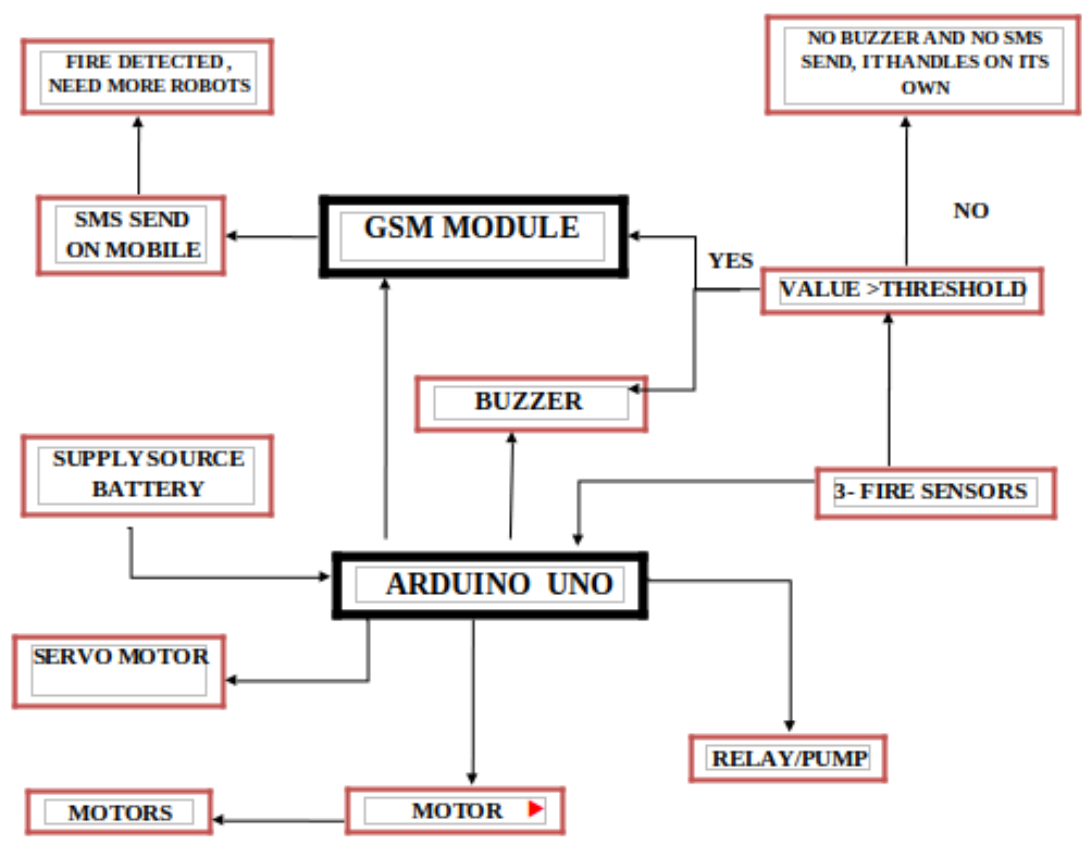

Fig. 4: Flow chart

\section{Description of some components:}

1. Arduino [14]: Microcontroller Board based on Atmega328P with multiple pins (6 analog and 14 digital pins). Arduino IDE is used toprogram the board. Power supply is applied by 9 volt external battery. It has 8 bit mirochip AVR, also has SRAM and Flash memory. There are various kind of other board which can be used according to the shape and numbers of pin ports required. They are nano, mega, lily pad, etc.

2. DC Motor and Motor driver [15]: The motor converts electrical energy into mechanical energy which is used to drive the system and the motor is driven by motor driver which works on basis of $\mathrm{H}$ bridge MOSFET. L293D is the most commonly used motor driver. Other drivers can be used according to the compatibility of motor.

3. IR Sensor [16]: It has a adaptibility of ambient light and has a infrared transmitter and receiver

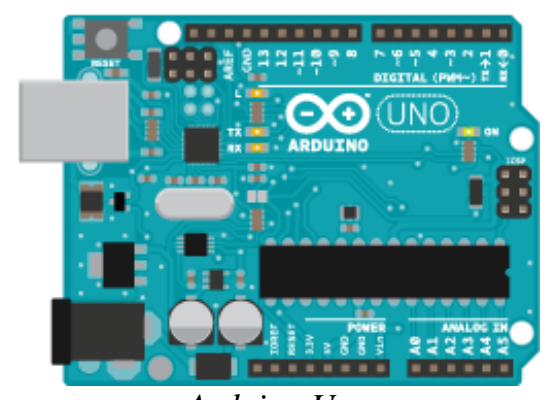

Arduino Uno which transmits and receives the light and generates the value based on the intensity of light received. If the light is received by the receiver it shows presence of light and value goes high and vice versa.

4. Water pump: It is used to generate suction which pull of the water from tank and deliver to desired location.

5. Servo Motor: It is the motor which progress its movement in step. It has a movement of 180 degree in both the direction and has movement of 1 degree in each step. It is a programmable motor which receives its pulses from PWM pin of the microcontroller board.

6. Relay: It has set of contact terminals which is used to make or break contacts between two terminals. It is an electromechanical switch which opens and closes the circuit.

7. Other components used are battery, GSM module, wheels and other connecting wires.

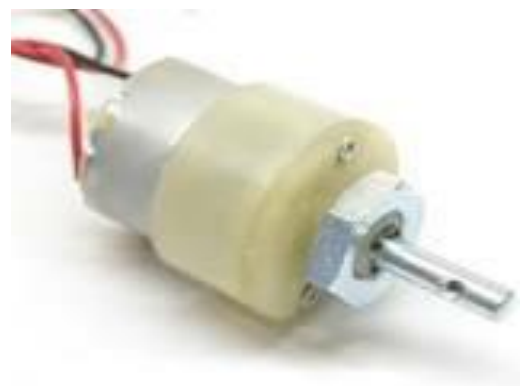

DC Motor 


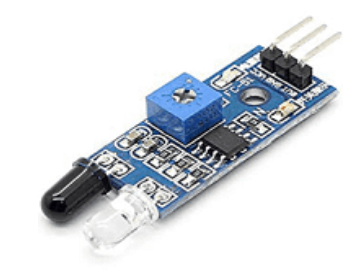

IR Sensor/ Flame Sensor

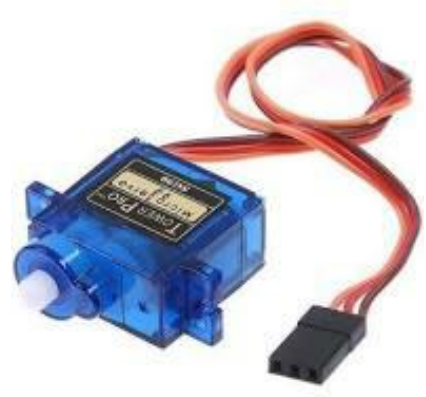

Servo Motor
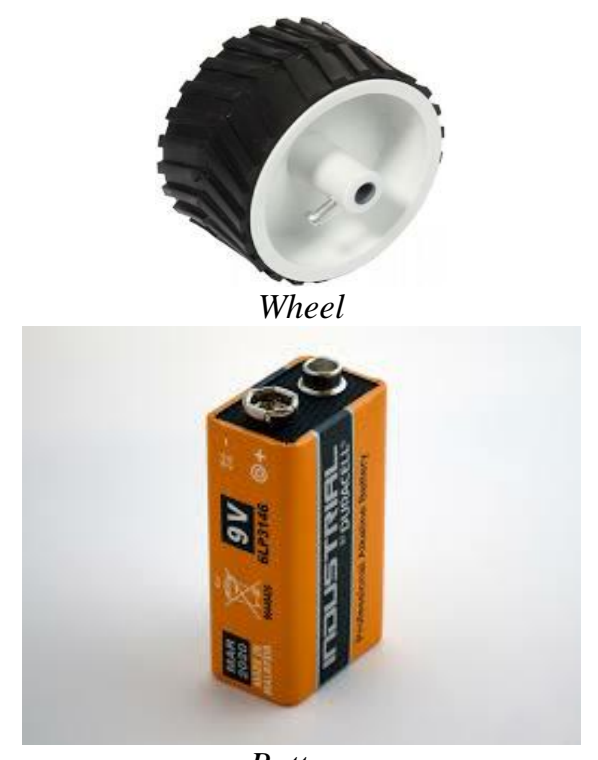

Battery
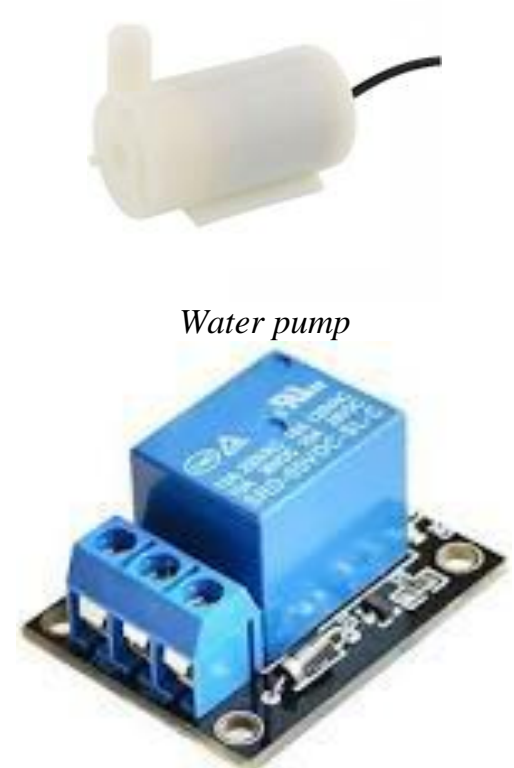

Relay

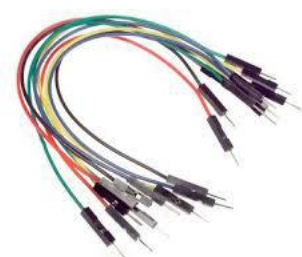

Wires

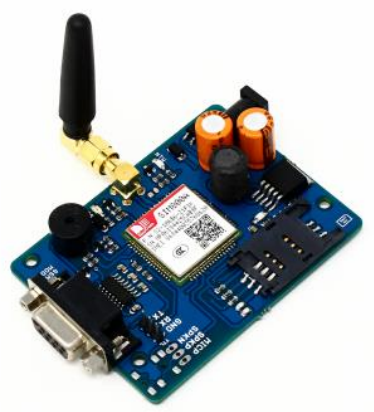

GSM Module

Fig. 5: Components Used in work

\section{CONCLUSION}

There are various paper and models available for autonomous fire fighter robot but only sending the robot to extinguish fire is not at all. But we even need to about the situation inside the room or space where it is in. So to discard these problem we have added the GSM module so that the system keeps on checking the intensity of fire inside any space and notify it to the nearest fire station or anyone who is incharge of the situation.

This makes our project more reliable then any other projects alike, and to even improve the performance of the robot more we can add camera which help give real time view of the situation and decision about sending in more robots or to just keep relaxing with the robot handling the job could be taken easily.

\section{ACKNOWLEDGEMENT}

I would like to express my special Thanks of Gratitude to My Project Mentor Prof. Balwant Singh for their able support and guidance in completing the Paper. I would also like to extend my gratitude to my Project Head Prof. V. K. Agarwal and my Head of Department Dr. RN Baral for providing me help in completing my Research Paper. 


\section{REFERENCES}

[1] V. K. Garg and T. S. Rappaport, Wireless network evolution: $2 G$ to $3 G$. Prentice Hall PTR, 2001.

[2] J. G. Andrews et al., "What will $5 \mathrm{G}$ be?," IEEE J. Sel. areas Commun., vol. 32, no. 6, pp. 1065-1082, 2014.

[3] S. Deng, "System for interconnecting packet-switched and circuit-switched voice communications." Google Patents, 29-Jul2003.

[4] R. M. Leatherbury and R. E. L. Johnson, "Time division multiplexing over broadband modulation method and apparatus." Google Patents, 13-Jul-2004.

[5] K. Murota and K. Hirade, "GMSK modulation for digital mobile radio telephony," IEEE Trans. Commun., vol. 29, no. 7, pp. 1044-1050, 1981.

[6] K. L. Stanwood and I. J. Klein, "System and method for wireless communication in a frequency division duplexing region." Google Patents, 04-Mar-2008.

[7] D. Calin and D. Zeghlache, "Performance analysis of high speed circuit switched data (HSCSD) over GSM," in Multiaccess, Mobility and Teletraffic, Springer, 1998, pp. 165-178.

[8] T. Halonen, J. Romero, and J. Melero, GSM, GPRS and EDGE performance: evolution towards 3G/UMTS. John Wiley \& Sons, 2004.

[9] D. Bladsjo, A. Furuskar, S. Javerbring, and E. Larsson, "Interference cancellation using antenna diversity for EDGE-enhanced data rates in GSM and TDMA/136," in Gateway to 21st Century Communications Village. VTC 1999-Fall. IEEE VTS 50th Vehicular Technology Conference (Cat. No. 99CH36324), 1999, vol. 4, pp. 1956-1960.

[10] M. Toorani and A. Beheshti, "Solutions to the GSM security weaknesses," in 2008 The Second International Conference on Next Generation Mobile Applications, Services, and Technologies, 2008, pp. 576-581.

[11] Y. J. Choi and S. J. Kim, "An improvement on privacy and authentication in GSM," in International Workshop on Information Security Applications, 2004, pp. 14-26.

[12] C.-C. Lee, M.-S. Hwang, and W.-P. Yang, "Extension of authentication protocol for GSM," IEE Proceedings-Communications, vol. 150, no. 2, pp. 91-95, 2003.

[13] H. D. Pham, M. Drieberg, and C. C. Nguyen, "Development of vehicle tracking system using GPS and GSM modem," in 2013 IEEE conference on open systems (ICOS), 2013, pp. 89-94.

[14] T. H. Nasution, M. A. Muchtar, I. Siregar,
U. Andayani, E. Christian, and E. P. Sinulingga, "Electrical appliances control prototype by using GSM module and Arduino," in 2017 4th International Conference on Industrial Engineering and Applications (ICIEA), 2017, pp. 355-358.

[15] E. H. E. Bayoumi and Z. A. Salmeen, "Practical swarm intelligent control brushless DC motor drive system using GSM technology," WSEAS Trans. Circuits Syst., vol. 13, pp. 188-201, 2014.

[16] P. Kumar and P. Kumar, "Arduino based wireless intrusion detection using IR sensor and GSM," Int. J. Comput. Sci. Mob. Comput., vol. 2, no. 5, pp. 417-424, 2013. 